\title{
O DESIGNER GRÁFICO NOS SETORES DA INDÚSTRIA E PRESTAÇÃO DE SERVIÇOS NA REGIÃO SUL DE SANTA CATARINA SOB OS OLHOS DO MERCADO
}

The graphic designer in industry and service sectors in the south region of Santa Catarina under the eyes of the market

\author{
DA SILVA, Patrícia Mendes; Bacharela; Faculdade SATC \\ patriciaameendes@gmail.com \\ MEDEIROS, Diego Piovesan; Doutor; Faculdade SATC \\ diego.medeiros@satc.edu.br
}

\section{Resumo}

Esta pesquisa tem como objetivo, conhecer a percepção em relação ao profissional do design gráfico nos setores da indústria e prestação de serviços na região da AMREC, cidades que compõem a região carbonífera de Santa Catarina, e compará-las. Para o desenvolvimento do objetivo proposto, foi realizada uma pesquisa e discussão de autores relacionados ao tema, como Niemeyer (2007), Cardoso (2012) e Bonsiepe (2012), bem como a apresentação da metodologia e ferramenta de pesquisa utilizada. Após a fundamentação do tema e métodos, a pesquisa foi aplicada em empresas da região da AMREC no sul de Santa Catarina. Por fim foram analisados e discutidos os resultados obtidos pela realização da pesquisa.

Palavras Chave: Design gráfico; Profissional; Mercado de trabalho.

\begin{abstract}
The objective of this research is tounder stand the perception of graphic design professionals in the industry and services sectors in the AMREC region, which compares the Santa Catarina coalregion, andto compare them. For the development of the proposed objective, a research and discussion ofa uthors related to the theme, such as Niemeyer (2007), Cardoso (2012) and Bonsiepe (2012) we recarried out, as well as the presentation of the methodology and research tool used. After the foundation of the theme and methods, there search was applied in companies of the AMREC region in thesouthof Santa Catarina. Finally, the results obtained by there search were analyzed and discussed.
\end{abstract}

Keywords: Graphic design; Professional; Market. 


\section{O ESTUDO EM DESIGN: UM BREVE PANORAMA}

O estudo em design no Brasil, conforme Niemeyer (2007), foi estimulado a partir da década de 1960 no Rio de Janeiro. Em 1975 já funcionavam no país 15 graduações em design, todas elas com referência nos métodos de ensino da ESDI (ALVARES, 2004), baseados em práticas de ateliê e com muito pouco conteúdo teórico.

Cardoso (2012) avalia que a institucionalização do ensino da profissão no país na década de 1960 possuía muito mais intenção ideológica do que pedagógica, com professores de pouca experiência didática e profissional.

Conforme Alvares (2004), a falta de preparo dos docentes, o superficialismo das teorias e o destino incerto dos acadêmicos fez com que ações fossem aplicadas para minimizar esses problemas. Algumas dessas ações segundo a autora (2004) foram o apoio à pesquisa em design por instituições governamentais, como CAPES e CNPq, e a criação de um currículo mínimo para os cursos superiores em design em 1987.

Este currículo mínimo citado pela autora (2004) foi atualizado e publicado em uma resolução pela Câmara de Educação Superior em 2004, onde as diretrizes curriculares dos cursos superiores em design no país são aplicadas de forma generalizada. Segundo a resolução, as instituições de ensino têm a possibilidade de adotar no curso uma modalidade específica da profissão, adequando a grade curricular às necessidades do mercado da sua região.

De acordo com o documento, todo curso superior em design deve contemplar em seus projetos conteúdos e organização curricular atividades que estejam diretamente ligadas aos pontos apresentados no quadro a seguir:

Quadro1 - Diretrizes do ensino superior em design no Brasil

\begin{tabular}{l|l}
\hline \multirow{2}{*}{ Conteúdos básicos } & $\begin{array}{l}\text { Estudo da história e das teorias do design em seus contextos sociológicos, } \\
\text { antropológicos, psicológicos e artísticos, abrangendo métodos e técnicas de projetos, } \\
\text { meios de representação, comunicação e informação, estudos das relações } \\
\text { usuário/objeto/meio ambiente, estudo de materiais, processos, gestão e outras relações } \\
\text { com a produção e o mercado; }\end{array}$ \\
\hline Conteúdos específicos & $\begin{array}{l}\text { Estudos que envolvam produções artísticas, produção industrial, comunicação visual, } \\
\text { interface, modas, vestuários, interiores, paisagismos, design e outras produções } \\
\text { artísticas que revelem adequada utilização de espaços e correspondam a níveis de } \\
\text { satisfação pessoal; }\end{array}$ \\
\hline Conteúdos & $\begin{array}{l}\text { Domínios que integram a abordagem teórica e a prática profissional, além de peculiares } \\
\text { desempenhos no estágio curricular supervisionado, inclusive com a execução de } \\
\text { teórico-práticos }\end{array}$ \\
\hline
\end{tabular}

\section{Fonte: CNE/CES (2004)}

Embora as diretrizes publicadas pelo CNE/CES (2004) relacionem as propostas de conteúdo das graduações de design com o mercado, para Landim (2010), a demanda de profissionais formados pelos cursos é muito maior do que sua necessidade no mercado. Conforme um relatório elaborado pelo SEBRAE em 2014, o cenário educacional do design no Brasil encontra-se distribuído conforme o quadro a seguir: 


\begin{tabular}{l|c}
\multicolumn{2}{c}{ Quadro2 - Relatório 2014 setor do Design } \\
\hline Cursos de Tecnólogos & 229 \\
\hline Cursos de Bacharelado & 223 \\
\hline Cursos de Pós Lato Sensu & 93 \\
\hline Cursos de Pós Stricto Sensu & 15 \\
\hline Eventos Acadêmicos & 27 \\
\hline Bolsas de Estudo & 76 \\
\hline Instituições que promovem Pesquisa em Design & 23 \\
\hline Incubadoras de Design & 11 \\
\hline Centros de Design & 11 \\
\hline Associação de Classe & 19 \\
\hline Prêmios e Concursos & 43 \\
\hline Portais, sites e Blogs & 90 \\
\hline Revistas & 63 \\
\hline Boletins & 12 \\
\hline Programas de Incentivo ao Design & 13 \\
\hline Editorias & 15 \\
\hline Exposições, Mostras e Feiras & 52 \\
\hline Fontes de financiamento e fomento & 19 \\
\hline Núcleos de Design & 20 \\
\hline
\end{tabular}

Fonte: SEBRAE (2014)

A pesquisa realizada pelo SEBRAE já possui quatro anos e entende-se que estes números já devam ter modificado, mas não implicam com os entendimentos aqui analisados. Percebendo os dados do quadro, é possível observar uma discrepância entre o número de cursos voltados ao design e os órgãos disseminadores da profissão, como centros, incubadoras e núcleos de design. Para Bonsiepe (2012), a implantação de mais centros experimentais de design seria a ponte entre o ensino das universidades e o campo profissional, unindo os conteúdos disciplinares com a prática de projeto. Pode-se também ressaltar os dados da organização profissional dos designers no país, pois apesar de não ser uma profissão regulamentada, os profissionais estão muito bem organizados em 19 associações de classe.

Conforme Cardoso (2012), o questionamento da qualidade do ensino superior no Brasil abrange toda política educacional no país e não somente na área de design. Porém, segundo o autor (2012), em algumas áreas como direito e medicina a condição de aprendiz de um recémformado é muito clara. Ao terminar a faculdade os estudantes dessas áreas são tratados como formados e não como profissionais, pois antes de serem reconhecidos como profissionais da área precisam passar por diversas etapas de validação e aprofundamento. Entretanto, no design um recém-formado já é considerado profissional, o que acaba desqualificando o ensino, pois se não há validação não existe o reconhecimento das limitações (CARDOSO, 2012).

Landim (2010) concorda que esse posicionamento dos estudantes de design está muito distante da realidade das empresas. Conforme a autora (2010), o mundo fantasioso de grandes corporações e empresas modernas empregado nas universidades acaba gerando frustrações nos estudantes que saem das graduações e encontram um cenário totalmente diferente do esperado.

Uma das falhas do ensino em design no Brasil, para Bonsiepe (2012), é a falta de interação com disciplinas distintas, como desenho industrial e engenharias. Ainda segundo o autor (2012), a ligação entre a universidade e o contexto industrial e social em que se encontra é muito precária. Essa falta de ligação acaba por deixar para trás projetos de inovação desenvolvidos por estudantes das universidades, que acabam se inibindo por seus projetos bloqueados (BONSIEPE, 2012).

Para Cardoso (2012), o grande desafio das universidades é desconstruir a imagem de falta de intelectualismo no ensino de design. Essa desconstrução, conforme o autor (2012), só será 
possível com a integração entre projeto, pesquisa, prática profissional e atividades culturais. Apesar da sala de aula ser algo restrito em relação aos desafios que o mercado prevê, cabe aos alunos e professores saber integrar o design a outras disciplinas e instâncias, tornando o aprendizado mais verdadeiro e próximo ao campo profissional (CARDOSO, 2012).

Cada área de atuação possui seus desafios específicos, e o recorte desta pesquisa focará no Design Gráfico, onde as perspectivas e relação do profissional com o mercado brasileiro serão abordadas na próxima seção, apresentando os desafios e atividades do designer gráfico no Brasil.

\section{O PROFISSIONAL E SEUS DESAFIOS}

Apesar da nomenclatura designer gráfico ser um termo recente (ADG, 2010), atualmente ainda existe muita confusão em relação à prática e exercício da profissão. Tratando-se das competências designadas ao profissional designer, encontra-se um cenário muito mal definido em relação às condições de acesso e exercício da profissão (NIEMEYER, 2007).

Para Silva (2014), o corpo teórico do design é formado a partir do estudo de outras atividades, fazendo com que o posicionamento da profissão fique fragilizado frente a essas áreas já profissionalizadas, como publicidade, arquitetura e até mesmo engenharia. Conforme a autora (2014), as práticas de design exercidas por outros profissionais acaba gerando conflito e confundindo a função do design com a função dessas demais profissões.

Segundo Wollner (2010), um empresário que precisa de design mas não tem conhecimento do que isso é exatamente, pode chamar qualquer profissional que tenha intuição e talento, entretanto esse mesmo profissional, não estará preparado para aplicar a tecnologia ao projeto e menos ainda em fazer design.

Segundo o Código de Ética profissional elaborado pela Associação Brasileira dos Designers Gráficos, o primeiro dever do profissional no desempenho de suas funções deve ser: "Interessarse pelo bem público e com tal finalidade contribuir com seus conhecimento, capacidade e experiência para melhor servir à sociedade", corroborando com a ideia de Landim (2010) de que o papel do designer vai muito além do projeto de um produto.

Apesar da sua importante função na sociedade, o designer ainda sofre com as perspectivas de mercado e inserção no meio empregatício. Conforme Cardoso (2004), muitos jovens concluintes de graduação em design são cercados de ameaças sobre o futuro que os aguarda. Todavia, segundo o autor (2004), apesar de ser um mercado assustador para os iniciantes, sem nenhum tipo de garantia, o mercado brasileiro para os designers é cheio de possibilidades.

Para a ADG (2010), são inúmeros os campos de atuação do designer gráfico, porém a associação fez uma seleção de sete grandes áreas em que o profissional está inserido, sendo elas: identidade corporativa, publicações institucionais, design editorial, embalagem, material promocional, design ambiental e mídia eletrônica. Embora a ADG (2010) classifique os campos de atuação do designer em sete grandes áreas, para a ICOGRADA (International Council Of Graphic Design Associations) ${ }^{1}$, o designer gráfico é responsável pelo desenvolvimento de todas as formas visuais, sejam elas on-line ou off-line. Entre estas áreas a instituição inclui: construção de tipografias, fotografias e desenvolvimento da interface de jogos e animações.

\footnotetext{
${ }^{1}$ Disponível em:< http://www.ico-d.org/>. Acesso em: 05 mar. 2016.
} 
Quadro 3 - Áreas de atuação do designer gráfico

\begin{tabular}{|c|c|}
\hline Área & Características \\
\hline Identidade Corporativa & $\begin{array}{l}\text { Atividade mais conhecida como prática do design gráfico, mas apesar do que muitos ainda } \\
\text { pensam, o projeto de identidade corporativa vai muito além da criação de uma marca e está } \\
\text { ligado à projeção de sistemas, planejando estrategicamente a imagem da empresa em estudo. }\end{array}$ \\
\hline $\begin{array}{l}\text { Publicações } \\
\text { Institucionais }\end{array}$ & $\begin{array}{l}\text { É nas publicações institucionais compostas por catálogos, relatórios anuais e peças de divulgação } \\
\text { que todo o projeto de identidade visual será aplicado. Porém, ainda que seja preciso manter o } \\
\text { padrão pré-definido, deve se ter muito cuidado, equilibrando a linguagem da marca padronizada } \\
\text { e a novidade na linguagem gráfica institucional. }\end{array}$ \\
\hline Design Editorial & $\begin{array}{l}\text { Nessa área são desenvolvidos todos os de projetos como livros, revistas e jornais. É no design } \\
\text { editorial que o profissional encontra dificuldade para inovação, normalmente o design está } \\
\text { somente aplicado na capa dessas publicações, porém pode e deve se ir muito além, inserindo o } \\
\text { design também nos miolos, desenvolvendo projetos mais criativos, interativos e interessantes, } \\
\text { tanto para a editora quanto para o leitor. }\end{array}$ \\
\hline Mídia Eletrônica & $\begin{array}{l}\text { Na mídia eletrônica estão inclusos projetos digitais, como televisivos e websites. Esse tipo de } \\
\text { projeto se assemelha muito ao de embalagem e design editorial, buscando sempre passar a } \\
\text { mensagem de forma clara e de fácil entendimento pelo consumidor. }\end{array}$ \\
\hline Design Ambiental & $\begin{array}{l}\text { Este trata de todos os projetos de sinalização e ambientação, tanto de edifícios, espaços } \\
\text { comerciais e exibições como estandes e feiras. O design ambiental tem como função otimizar o } \\
\text { processo nesses ambientes por meio de sinalização, placas, estando sempre de acordo com o } \\
\text { lugar em que será aplicado. }\end{array}$ \\
\hline Material Promocional & $\begin{array}{l}\text { Dentre as áreas que o designer atua, esta é a que possibilita maior diversidade, podendo ser } \\
\text { desde um projeto de ponto de venda, um brinde de final de ano ou um cartaz de filme de arte. } \\
\text { Apesar da aproximação com a publicidade, o papel do designer no desenvolvimento de material } \\
\text { promocional consiste em realmente criar o produto do zero, inovando de alguma forma, seja no } \\
\text { formato ou na utilização. }\end{array}$ \\
\hline Embalagem & $\begin{array}{l}\text { Nesse ramo do design quem comanda os projetos são os números. Ainda que em outros } \\
\text { projetos o público e uma pesquisa de mercado e concorrência não seja tão valorizada, no } \\
\text { desenvolvimento de embalagens essa pesquisa é essencial. Nesse tipo de projeto é importante } \\
\text { que o designer tenha conhecimento do seu público e consiga por meio da embalagem ir muito } \\
\text { além do produto oferecido e criar uma espécie de relação e fidelidade com o consumidor. }\end{array}$ \\
\hline
\end{tabular}

Fonte: ADG (2010)

Uma das ações para inserção e posicionamento do profissional no mercado é o processo de regulamentação do designer, que segundo Braga (2007) foi elaborado pela ABDI e apresentado para o deputado Athiê Coury em 1980, e três anos depois arquivado pela Câmara de Deputados. Conforme a CBD $^{2}$ (2014), em 2013, com a aprovação no senado do Projeto de Lei no 1.391, houve um grande avanço e uma esperança de que de fato ocorresse a regulamentação da profissão. Porém, em 2015 o projeto foi vetado pela presidente Dilma Roussef, seguindo novamente para exame do Congresso (AGÊNCIA SENADO, 2015).

Apesar de ser um ponto essencial para o reconhecimento do profissional, para Strunck (2010) o processo de regulamentação não irá resolver os problemas da desvalorização da profissão, para o autor (2010) a desvalorização está ligada à baixa demanda de trabalho.

Porém, Strunck (2010) e Camp (2010) compartilham da ideia de que a regulamentação daria ao profissional a segurança de que sua formação acadêmica seria remunerada de forma adequada a seu nível de certificação, além de dar a possibilidade ao profissional de possuir registro, participação e concorrência justa em concursos e licitações públicas e de empresas de grande porte. Entretanto, apesar dessas vantagens que a regulamentação daria à profissão, cabe também ao designer gráfico capacitado colaborar para que a visão do mercado seja positiva e

\footnotetext{
${ }^{2}$ Centro Brasil Design.
} 
adequada em relação ao profissional, mostrando que o design pode ser utilizado estrategicamente no mercado, dando mais capacidade ao que for aplicado (LANDIM, 2010).

\section{UM OLHAR LOCAL: PROCEDIMENTOS TÉCNICOS DE COLETA DE DADOS}

A fim de realizar a pesquisa de levantamento, foi utilizado como ferramenta de coleta de dados um questionário on-line. Segundo Marconi e Lakatos (2010), o questionário é um instrumento constituído por perguntas que devem ser respondidas sem a presença do entrevistador. Conforme as autoras (2010), o questionário é enviado ao correspondente, é preenchido e devolvido ao pesquisador, sem contato direto.

O questionário foi enviado para gestores e contratantes de designers, dos setores da indústria e prestação de serviços entre outubro e novembro de 2016, tendo o intuito de conhecer suas percepções em relação ao profissional do design gráfico. Se tratar de uma pesquisa de levantamento por amostragem, foram escolhidas indústrias e empresas de prestação de serviços de municípios que compõem a AMREC no Sul de Santa Catarina (Associação dos Municípios da Região Carbonífera), sendo eles: Balneário Rincão, Cocal do Sul, Criciúma, Forquilhinha, Içara, Lauro Müller, Morro da Fumaça, Nova Veneza, Orleans, Siderópolis, Treviso e Urussanga.

A partir desses municípios foi feito um levantamento das indústrias e empresas dessas cidades que atuam nos segmentos e setores em que o design gráfico está inserido, como será apresentado na primeira pergunta do questionário. Estes segmentos e setores foram identificados por meio dos campos de atuação do designer gráfico apresentado pela ADG (2010).

Feito esse levantamento e identificados os segmentos em que o designer gráfico atua, foram selecionadas 60 empresas, para envio do questionário para seus gestores e contratantes. Conforme Marconi e Lakatos (2010), em média o índice de retorno de questionários enviados é de $25 \%$ de respostas relevantes. Deste modo dentre os 60 questionários enviados, 22 (10 de prestação se serviços, 12 de indústria) foram preenchidos e devolvidos com informações suficientes para análise e conclusão da pesquisa, totalizando $36 \%$ de retorno.

Portanto, para esta pesquisa foi desenvolvido um questionário com oito perguntas, dentre elas cinco abertas e três fechadas. As perguntas foram elaboradas de acordo com os questionamentos e pontos levantados a partir das conclusões dos autores expostas nos dois capítulos anteriores, em conjunto com o objetivo geral desta pesquisa. Para a otimização deste artigo, as perguntas serão apresentadas ao decorrer da análise dos dados obtidos.

\section{ANÁLISE E DISCUSSÃO DOS DADOS OBTIDOS}

Este capítulo discute e analisa os dados obtidos na pesquisa apresentada no capítulo anterior, que tem como objetivo conhecer a percepção dos setores da indústria e prestação de serviços em relação ao profissional do design gráfico na região da AMREC e compará-las. Para melhor organização e entendimento das discussões, as respostas das oito perguntas obtidas por meio do questionário serão discutidas separadamente. A cada pergunta serão analisadas as respostas do setor de prestação de serviços, logo após do setor industrial e por fim as convergências e divergências das respostas dos dois setores. 
Os nomes das empresas participantes da pesquisa não serão divulgados, portanto, como apresentado na pergunta 1 do questionário, os setores e suas segmentações serão apresentados na análise da seguinte forma: (1) Prestação de serviços: agência, web, escritório de design e produtora; (2) Indústria: plástico e rotulagem, gráfica, cerâmico e vestuário.

\subsection{Percepção do profissional}

Esta seção está relacionada à seguinte pergunta do questionário: "Qual sua percepção em relação ao profissional do design gráfico no setor/segmento em que sua empresa atua?", avaliando como o mercado percebe a posição do profissional do design gráfico em cada setor.

\subsubsection{Prestação de serviços}

Avaliando as respostas dos representantes das empresas prestadoras de serviços relacionadas ao design gráfico, é possível identificar percepções bem próximas dos segmentos questionados neste setor. Este tratou o designer gráfico como grande responsável pelos serviços oferecidos pelas empresas. De acordo com os entrevistados, o designer gráfico está diretamente ligado à técnica e aspectos estéticos dos projetos desenvolvidos para seus clientes.

Segundo as agências, é este profissional que produz praticamente todo o material comercializado pela empresa, sendo agente inovador no mercado. Neste segmento o profissional é percebido como alguém capacitado para visualizar e solucionar problemas ligados à técnica, tornando-se fundamental como parte da equipe nas agências. O segmento de web avalia o profissional do design gráfico como responsável pela primeira etapa do projeto. Este segmento também relaciona a profissão somente à estética do serviço oferecido, atribuindo os aspectos funcionais a outros profissionais como programadores.

No segmento de escritório de design o profissional é percebido como limitado a questões técnicas e teóricas. Neste segmento é entendido que o design gráfico se trata de uma profissão interdisciplinar, porém se restringe ao conhecimento adquirido nas universidades. Já para produtoras o designer gráfico é que desenvolve toda parte visual do projeto, porém, assim como no segmento de web, os aspectos funcionais são atribuídos a outras profissões.

Em todos os segmentos de prestação de serviços é possível identificar uma semelhança na percepção do profissional, principalmente em relação à participação no processo de criação. 0 setor de prestação de serviços observa que este profissional participa somente das etapas relacionadas à função estética do produto, sem intervenção no projeto funcional.

\subsubsection{Indústria}

No setor industrial cada segmento possui uma percepção única do profissional. Por conta do setor da indústria ter produtos muito específicos, as empresas possuem avaliações distintas em relação ao designer gráfico. Para o segmento de plástico e rotulagem os profissionais do design gráfico da região não estão capacitados para atuar neste tipo de indústria. A demanda de profissionais especializados em flexografia e finalização de arquivos na indústria de plástico é muito escassa. Além da falta da escassez, este segmento encontra dificuldade de encontrar cursos e formações voltadas para esta área da indústria, principalmente na região da AMREC. O segmento gráfico também percebe a falta de profissionais qualificados, principalmente para edição e finalização de materiais. Apesar da falta de qualificação nesta área, para a indústria gráfica, este profissional é indispensável e tem papel importante na produção e desenvolvimento de novos produtos. 
Em relação à percepção da indústria cerâmica, este segmento alia o designer gráfico à técnica, inovação e habilidade em softwares gráficos. É por meio deste profissional que as cerâmicas se posicionam no mercado, pois o design gráfico está diretamente relacionado à principal atividade deste segmento, o design de superfície.

$\mathrm{Na}$ indústria do vestuário o designer gráfico é percebido como um diferencial no desenvolvimento de novos produtos. Neste segmento o profissional passou a ser fundamental. É por meio do designer que as empresas de vestuário expõem seus produtos como exclusivos e se destacam no mercado.

Apesar do setor industrial possuir percepções distintas, em alguns pontos os segmentos têm as mesmas dificuldades e visão em relação ao designer gráfico. De acordo com as respostas obtidas do setor industrial, o designer gráfico é um dos profissionais responsáveis pelo destaque do produto no mercado. Conforme os entrevistados, a qualidade dos produtos está atrelada à participação de um designer no processo, o que obriga que todas as empresas tenham um profissional de design em sua equipe, a fim de ter capacidade competitiva no mercado.

\subsubsection{Convergências e divergências entre os setores}

Uma das percepções que os setores estão em concordância é em relação à qualificação do profissional. No setor de prestação de serviços o designer gráfico se limita aos conhecimentos acadêmicos, tendo dificuldades de ampliar suas habilidades e se adaptar à realidade do mercado. Já na indústria o profissional ainda não possui qualificação adequada a determinados segmentos.

Em discordância entre os setores está a percepção quanto à participação do designer gráfico no processo de desenvolvimento dos produtos oferecidos. No setor industrial, o designer é percebido como um profissional atuante em todo processo de desenvolvimento, é visto como um sinônimo de inovação, sendo responsável pelo visual e diferencial dos produtos.

Em contraponto, no setor de serviços os segmentos apresentam o designer gráfico como um profissional voltado a habilidades teóricas e práticas. Para as empresas prestadoras de serviços, estes profissionais têm participação somente nos aspectos estéticos dos produtos desenvolvidos. Para Landim (2010), esta é uma visão errada do profissional, já que são inúmeras as habilidades designadas ao profissional do design gráfico.

\subsection{Atividades do profissional}

A seção a seguir fará análise da pergunta 3 do questionário, sendo ela: "Quais as principais atividades que o profissional do design gráfico desenvolve em sua empresa?", tendo como foco identificar se o profissional realmente desempenha as funções atribuídas ao designer gráfico. Cabe ressaltar que as respostas obtidas, são percepções dos contratantes e diretores das empresas participantes e não de profissionais com formação em design gráfico.

\subsubsection{Prestação de serviços}

As atividades desenvolvidas pelos designers gráficos nas empresas prestadoras de serviços, apesar de serem de diferentes segmentos, são similares em sua execução e objetivos.

Nas agências a principal atividade do designer está ligada à direção de arte. Para os gestores e contratantes deste segmento, atividades como desenvolvimento de embalagens, identidade visual e materiais de propaganda são relacionadas à direção de arte e é o designer que desempenha essa função. Para o segmento de web o profissional do design é quem desenvolve 
layout para sites, pequenas animações interativas e propaganda para redes sociais, contando com auxílio de softwares gráficos na construção destes materiais.

As atividades atribuídas ao designer gráfico no escritório de design são muito semelhantes às atividades nas agências. Porém, o planejamento e pensamento estratégico estão aliados à construção gráfica visual dos materiais. Para o escritório de design, a execução e planejamento estão diretamente ligados, dando a oportunidade do profissional assimilar como a estratégia influencia na criação visual. Nas produtoras, o designer gráfico é o profissional responsável pela diagramação e desenvolvimento de toda parte visual dos projetos.

No setor de prestação de serviços é notável que as atividades atreladas ao desenvolvimento gráfico e visual são tarefas de responsabilidade do designer gráfico. É possível identificar a falta de planejamento e pesquisa ligadas ao profissional, exceto no escritório de design, onde o designer tem participação em todo esse processo juntamente com a criação visual.

\subsubsection{Indústria}

$\mathrm{Na}$ indústria, as atividades de responsabilidade do designer gráfico possuem maior diversidade e estão ligadas à pesquisa e participação em todo o processo de criação. Em relação ao segmento de plástico e rotulagem, o profissional desempenha atividades como editoração gráfica e finalização de arquivos para impressão. Durante esse processo o designer deve levar em consideração principalmente as cores e os tamanhos dos materiais a serem produzidos.

No segmento gráfico, desenvolvimento de materiais impressos, como catálogos, é uma das funções do designer. Neste segmento o profissional também realiza tratamento de imagens e fechamento de arquivos para produção.

Dentro da indústria cerâmica são atribuídas ao designer gráfico várias etapas do processo de produção. No segmento cerâmico o designer é responsável por desenvolver novos produtos. Por meio de pesquisas de mercado e tendência, o profissional cria superfícies cerâmicas inovadoras, tanto em aspectos funcionais quanto estéticos. Outro papel do designer na cerâmica é sua participação nos processos finais. Todos os ajustes de cores e grafias são realizados pelo profissional quando o produto está entrando em linha de produção.

As funções desempenhadas pelos designers no segmento de vestuário são muito semelhantes às do segmento cerâmico. Atividades como tratamento de imagens, desenvolvimento de rapport e estampas são atribuídas ao profissional do design na indústria de vestuário. Além dessas atividades, o profissional também realiza pesquisa de tendência, desenvolvimento de conceito e calibragem de cores para produção.

Analisando as funções que o designer gráfico desempenha nos segmentos industriais, é possível identificar uma proximidade entre plástico e gráfico e também cerâmico e vestuário.

$\mathrm{Na}$ indústria de plástico e gráfica o profissional está mais relacionado à produção de materiais de terceiros e não à criação e desenvolvimento. Já nos segmentos cerâmico e vestuário, além da finalização para produção, os designers acompanham e participam de todo o projeto, desde a definição do conceito até a produção do produto.

\subsubsection{Convergências e divergências entre os setores}

Uma das divergências notáveis é a falta de pesquisa e planejamento relacionados ao profissional do design no setor de prestação de serviços, exceto no escritório de design. Conforme 
os entrevistados deste segmento, o designer gráfico somente executa projetos visuais. Em discordância a essa colocação, o MEC (2010) define as atividades do designer gráfico como desenvolvedor de projetos visuais, avaliando aspectos simbólicos, culturais, estéticos e socioeconômicos. Segundo a ADG (2010), a atividade do designer também vai além da execução de um projeto visual. Para a associação, o profissional está ligado à projeção de sistemas, planejando estrategicamente a imagem da empresa em estudo.

Seguindo os parâmetros definidos pelo MEC (2010) e pela ADG (2010), no setor industrial o designer gráfico está presente em todo processo de desenvolvimento de um produto. Nos segmentos cerâmico e vestuário essa participação fica evidente em pesquisas, definição de conceitos e finalização do produto.

No setor industrial a atuação do designer também está bem definida, exceto no segmento de vestuário, em que a atividade do designer gráfico se confunde com a do designer de moda. Mozota (2011) explica que o design de moda está relacionado ao desenvolvimento de produtos tridimensionais e o design gráfico a superfícies bidimensionais, incluindo a produção têxtil, portanto esta função deve ser atribuída ao designer gráfico, assim como no segmento cerâmico.

\subsection{Participação do profissional}

Nesta seção, serão abordadas as perguntas 5 e 6 do questionário. A pergunta 5 está relacionada ao profissional e quanto ele agrega ao produto final das empresas participantes, sendo ela: "Quanto a participação do profissional do design gráfico agrega ao seu produto final?". E pergunta 6 trata da presença do profissional do design gráfico nos processos de criação, sendo ela: "Em relação à inovação, criatividade e desenvolvimento de projetos em sua empresa, como você avalia a participação do profissional do design gráfico nesses processo?".

\subsubsection{Prestação de serviços}

Em relação a participação do profissional no processo de criação e quanto sua presença agrega ao produto final, os segmentos do setor de prestação de serviços possuem percepções semelhantes. De acordo com as respostas alcançadas, no segmento de agência o profissional agrega valor ao serviço prestado por meio de sua percepção e habilidades técnicas. Nas agências o designer possui uma diferenciação no momento de apresentar o produto ao cliente. Embora a participação do designer valorize o produto final, para os gestores e contratantes deste segmento, muitas vezes o profissional acaba se restringindo aos processos quando algum projeto é reprovado, causando frustração.

Esse tipo de atitude também é percebida no ramo de web. Neste segmento a participação do designer em conjunto com programadores é essencial para desenvolvimento e finalização de um produto, porém o profissional muitas vezes se sente preso ao habitual, não buscando novas alternativas para os projetos.

No escritório de design, o profissional participa ativamente dos desenvolvimento dos produtos, valorizando por meio de planejamento e criação gráfica, sendo incentivados a ampliarem suas habilidades em negócios e estratégia. Para as produtoras, a participação do profissional nos processos da empresa é essencial. Neste segmento a colaboração do designer nos projetos, passou a ser indispensável nos últimos anos, valorizando e aperfeiçoando a atividade do segmento. 
Por meio das respostas do setor de prestação de serviços, percebe-se uma dificuldade do profissional de demonstrar e utilizar suas habilidades não somente técnicas, mas também estratégicas no mercado de trabalho. Principalmente nos segmentos de web e agências, o designer se encontra preso ao comum e frustrado ao ter projetos reprovados. Embora em alguns segmentos o profissional tenha pouca participação no desenvolvimento de projetos, todos os ramos prestadores de serviços avaliam a presença do designer como sendo fundamental e agente da valorização dos produtos e serviços prestados.

\subsubsection{Indústria}

Em relação a participação do designer no processo criativo e na valorização do produto, os segmentos do setor industrial o avaliam como um dos responsáveis pelo sucesso dos produtos. Para a indústria de plástico o designer gráfico está presente em todos os processos de produção. Apesar de ser fundamental na valorização dos produtos, este segmento observa uma deficiência em relação a processos de inovação, criatividade e desenvolvimento por conta da carência de profissionais especializados neste ramo.

No segmento gráfico, o designer além de estar presente em grande parte das ações das empresas, é este profissional que fideliza o cliente. É pela qualidade de diferenciação que o designer proporciona aos clientes que o segmento gráfico valoriza seus produtos. A indústria cerâmica avalia que a presença do designer juntamente a área técnica estão diretamente relacionadas ao sucesso dos produtos. Para este segmento, o consumo está atrelado principalmente ao design oferecido pela empresa. Esta avaliação também é percebida no setor de vestuário. Neste a participação do designer na busca por inovação e criatividade é o que diferencia as empresas e destaca seu produto no mercado do vestuário.

Analisando as respostas dos segmentos industriais, é possível identificar a forte influência que a aplicação do design gráfico tem ao produto final. Outra observação feita por estes segmentos é a presença do designer em processos de inovação, criatividade e desenvolvimento. $\mathrm{Na}$ maioria das empresas entrevistadas o designer é o profissional que busca a diferenciação no mercado, participando de todos os processos de produção.

\subsubsection{Convergências e divergências entre os setores}

Nas empresas prestadoras de serviços o profissional é fundamental para agregar valor nos produtos. De acordo com este setor, o designer gráfico é atuante nas empresas e total responsável pelo produto final, exceto no segmento de web que as atividades são desenvolvidas em conjunto com programadores. No setor industrial o profissional também é avaliado como indispensável. Neste setor o design dos produtos em oferta são ponto decisivo na compra, e este papel é atribuído ao designer gráfico, que assim como no segmento de web, nas cerâmicas está atrelado ao setor técnico.

Em relação a participação do designer nos processos de inovação, criação e desenvolvimento os setores em estudo possuem percepções divergentes. Para a indústria o designer participa ativamente destes processos, estando sempre em busca de diferenciação e métodos criativos que estimulem a inovação. Porém no setor de prestação de serviços, as empresas observam profissionais presos ao habitual, onde, projetos reprovados causam frustração e bloqueiam a criatividade. Bonsiepe (2012), explica que pela falta de 
interdisciplinaridade nos cursos de design e a pouca relação com a realidade do mercado, causa nos recém formados essas frustração ao terem seus projetos bloqueados.

Outro fator ligado ao bloqueio criativo é a ideia de que um designer gráfico recém formado deve ser tratado como um profissional experiente. Cardoso (2012) expõe, que essa visão é muita clara nos setores em que o designer atua. Para o autor (2012), as empresas avaliam os recém formados em design e como profissionais com vasta experiência, quando na realidade deveriam ser recebidos no mercado sob condição de aprendizes.

\subsection{Ensino do design gráfico}

Está seção irá analisar os dados alcançados nas perguntas quantitativas do questionário, sendo elas: "Quantos profissionais do design gráfico fazem ou já fizeram parte do quadro de funcionários da sua empresa?", "Os profissionais que atuam ou atuaram na sua empresa possuem formação superior ou graduação em design gráfico" e "Como você classificaria as habilidades adquiridas pela formação acadêmica do profissional de design gráfico?". Estas perguntas tiveram o objetivo de conhecer a percepção dos setores em relação ao ensino do design na região, sua valorização e investimento nesses profissionais.

\subsubsection{Prestação de serviços}

Dentre estes profissionais que atuam nos segmentos de empresas prestadoras de serviços, ainda que a maioria possua formação superior, o número de profissionais sem formação também é alto, $60 \%$ dos profissionais que atuam nas empresas participantes possuem formação em design gráfico e $40 \%$ não possuem.

Esses números justificam algumas percepções distorcidas destes segmentos, principalmente em relação a contribuição do designer para o processo criativo e estratégico. Outro dado obtido por meio da pesquisa, foi a percepção que os gestores e contratantes de designers têm acerca do ensino do design gráfico na região da AMREC. A maioria dos participantes consideram que o ensino seja de nível mediano.

Figura 1 - Gráfico: Prestação de serviços - Nível de ensino

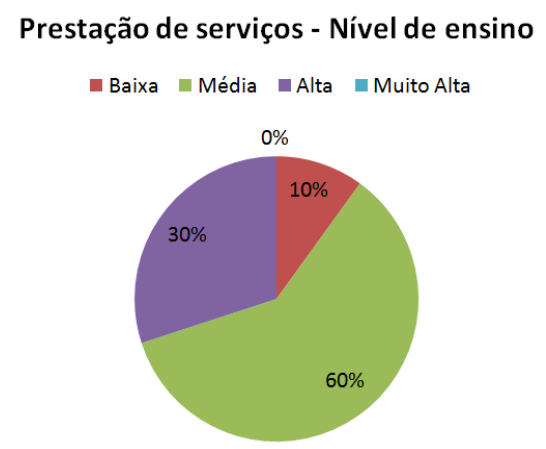

Fonte: Dos autores

Essa percepção pode ser entendida como uma falta de conhecimento do papel do designer e sua contribuição no mercado. Conforme algumas perguntas analisadas anteriormente, o setor de prestação de serviços não reconhece o profissional como agente estratégico nas empresas. Por avaliarem o designer dessa forma, consideram o ensino da profissão de nível mediano. Apesar desta avaliação, $30 \%$ dos participantes acreditam que o ensino tenha um nível alto, o que 
demonstra o reconhecimento do mercado e uma boa perspectiva do profissional e sua bagagem acadêmica.

\subsubsection{Indústria}

Em relação a graduação destes profissionais que atuam no setor da indústria as perspectivas são boas, $75 \%$ dos profissionais que trabalham no setor industrial possuem formação superior. Esta dado está relacionado a valorização do profissional neste setor e ao entendimento das possibilidades que a academia agrega ao profissional.

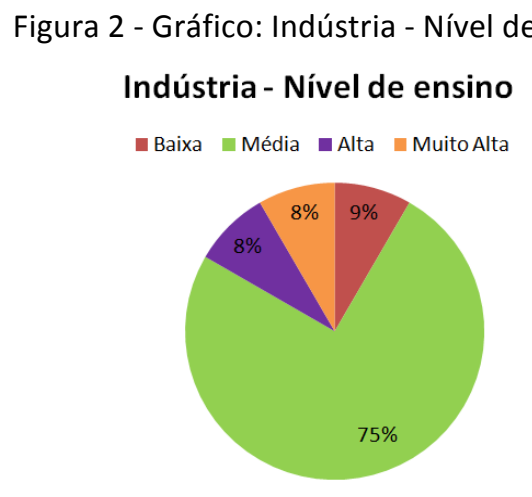

Fonte: Dos autores

Ainda que a indústria valorize a formação superior do profissional, a maioria das empresas participantes da pesquisa, avaliam o ensino do design gráfico na região da AMREC como nível mediano. Essa percepção pode ser entendida a partir das discussões anteriores, em que o acadêmico muitas vezes precisa passar por treinamentos e cursos, a fim de atender as necessidades de cada segmento da indústria.

Por meio das respostas obtidas é possível perceber a falta de cursos e especializações específicas para cada segmento da indústria. Essa avaliação das empresas participantes também está relacionada a carência de interação entre academia e mercado.

\subsubsection{Convergências e divergências entre os setores}

Conforme os resultados alcançados por meio das perguntas, é notável que o setor industrial possui um quadro maior de designers atuantes do que o setor de prestação de serviços. Esse investimento menor no setor de prestação de serviços pode ser identificado na percepção de Silva (2014), a autora expõe que em algumas áreas a valorização do profissional do design gráfico é menor por se confundir com áreas como publicidade e marketing.

Outro ponto divergente entre os setores está ligado a profissionais com formação superior em design. No setor industrial $75 \%$ dos profissionais possuem curso superior, enquanto no setor de prestação de serviços somente $60 \%$ possui formação superior. Essa percepção em relação a importância do estudo em design também se dá pelos conflitos entre o design e outras profissões.

Em relação ao nível do ensino de design na região, os setores concordam que o ensino é de nível mediano. Porém essa percepção está relacionada a fatores diferentes. Para o setor industrial, a falta de preparo do profissional para áreas específicas da indústria é um dos fatores que levam a essa avaliação. No setor de prestação de serviços essa visão do nível do ensino se dá pela falta de conhecimento das possibilidades que a academia agrega ao profissional. 


\section{CONCLUSÃO}

Esta pesquisa teve importância para conhecimento da percepção do mercado da AMREC em relação ao profissional do design gráfico, e compará-las entre os setores avaliados. Por meio da pesquisa foi possível identificar as divergências e convergências dos setores da indústria e prestação de serviços, discutindo os pontos positivos e negativos das respostas obtidas.

Conforme apresentado, ainda que os setores de indústria e prestação de serviços possuam divergências em suas percepções, para a autora em alguns pontos os setores possuem visões bem próximas. Em ambos os setores, o profissional é percebido como um agente técnico nas empresas, essa visão distorcida está ligada a falta de conhecimento por parte dos gestores e donos de empresas sobre as possibilidades que esses profissionais podem oferecer.

No setor industrial, nos segmentos cerâmico e têxtil é possível identificar maior participação do designer gráfico nos fatores estratégicos e em todo o processo de fabricação do produto. Entretanto, nas empresas de prestação de serviços e nos segmentos industriais de plástico e gráfico, essa participação está apenas na execução dos aspectos visuais dos projetos desenvolvidos. Para a autora, essa falta de conhecimento da real atividade do designer nas empresas está relacionada a conexão de universidade e mercado, na busca por identificar quais as necessidades de cada segmento.

Outro fator que leva os gestores e contratantes de designer a esse entendimento, é a dificuldade que os acadêmicos possuem de relacionar os métodos estratégicos utilizados na universidade a projetos desenvolvidos no mercado. Ao se formarem e ingressarem no mercado de trabalho os estudantes se deparam com uma realidade distante daquela apresentada nos cursos superiores, causando esse conflito de atividades. Apesar de algumas percepções distorcidas da profissão, com a pesquisa foi possível identificar a importância deste do design no mercado da região. Boa parte das empresas entrevistadas afirmaram que o designer é fundamental para finalização dos produtos. Demonstrando que o mercado está atento ao design e aplicando cada vez mais em seus projetos. Além de possibilitar o conhecimento da percepção dos diferentes segmentos em relação ao profissional, a pesquisa também identificou falhas e acertos na relação ensino e mercado, sugerindo e possibilitando novas soluções para que essa relação se torne cada vez mais estreita, contribuindo para o desenvolvimento e valorização da profissão na região.

\section{REFERÊNCIAS}

ABD. DESIGNER DE INTERIORES. Disponível em: < http://www.abd.org.br/novo/designers-deinteriores.asp>. Acesso em: 04 abr. 2016.

ADG et al. $O$ valor do design: guia ADG Brasil de prática profissional do designer gráfico. 5. ed. São Paulo: Editora Senac, 2010.

ADG. CENSO ADG. 2012. Disponível em: <http://www.adg.org.br/institucional/censo-adg>. Acesso em: 27 mar. 2016.

ALVARES, Maria Regina. Ensino do Design: A interdisciplinaridade na Disciplina de Projeto em

Design. 2004. 163 f. Dissertação (Mestrado) - Curso de Engenharia de Produção, Ufsc, Florianópolis, 2004 
AMREC. Municípios Associados. 2015. Disponível em: <http://www.amrec.com.br>. Acesso em: 27 mar. 2016.

BONSIEPE, Gui. Design como prática de projeto. São Paulo: Blucher, 2012.

BRAGA, Marcos da Costa . ABDI: História Concisa da Primeira Associação Profissional de Design do Brasil. Revista D.: design, educação, sociedade e sustentabilidade, v. 1. Porto Alegre: UniRitter, 2007. p. 13-32

CAMP, Freddy Van. REGULAMENTAÇÃO DO DESIGNER. A QUEM INTERESSA? 2010. Disponível em: <http://www.designbrasil.org.br/entre-aspas/regulamentacao-designer-quem-interessa/\#.VtWXvkrLIU>. Acesso em: 27 mar. 2016.

CARDOSO, Rafael. Design para um mundo complexo. São Paulo: Cosac Naify, 2012.

CARDOSO, Rafael. Uma Introdução a história do design. São Paulo: Blucher, 2004.

CBD, Centro Brasil Design. Diagnóstico do Design Brasileiro. 2014. Disponível em:

<http://www.cbd.org.br/wp-content/uploads/2013/01/Diagnostico_Design_Brasileiro_Web.pdf>. Acesso em: 27 mar. 2016.

CNE/CES. Diretrizes Curriculares Nacionais do Curso de Graduação em Design. 2004. Disponível em: <http://portal.mec.gov.br/cne/arquivos/pdf/rces05_04.pdf>. Acesso em: 8 mar. 2016

ICOGRADA. ICOGRADA Design Education Manifesto 2011. 2011. Disponível em: <http://www.icod.org/database/files/library/IcogradaEducationManifesto_2011.pdf>. Acesso em: 26 abr. 2016.

LANDIM, Paula da Cruz. DESIGN, EMPRESA, SOCIEDADE. São Paulo: Cultura Acadêmica Editora / Editora UNESP, 2010. v. 1. 191p.

MARCONI, Marina de Andrade; LAKATOS, Eva Maria. Fundamentos da metodologia científica. 7. ed. São Paulo: Atlas, 2010.

NIEMEYER, Lucy. Design no Brasil: origens e instalação. 4.ed. Rio de Janeiro: 2AB, 2007. v.1. 136p .

SEBRAE (Org.). Design no Brasil: relatório 2014 do setor de design. Brasília: Sebrae, 2014.

SENADO, Agência. Vetada regulamentação da profissão de designer. 2015. Disponível em: <http://www12.senado.leg.br/noticias/materias/2015/10/28/vetada-regulamentacao-daprofissao-de-designer>. Acesso em: 27 mar. 2016.

SILVA, Glaucia Aparecida da. A ideia é o valor mais importante no design: trabalho criativo no design gráfico. 2014. 107 f. Dissertação (Mestrado) - Curso de Sociologia, UFSCar, São Carlos, 2014.

STRUNCK, Gilberto. Viver de Design. Rio de Janeiro: 2AB, 2010.

WOLLNER, Alexandre. A identidade toma corpo. In: ADG et al. O valor do design: guia ADG Brasil de prática profissional do designer gráfico. 5. ed. São Paulo: Editora Senac, 2010. 